\title{
Effect of leukaemia therapy on neutrophil chemotaxis
}

\author{
EILEEN N THOMPSON AND SARAB-AL-NAKEEB \\ From the Department of Child Health, Welsh National School of Medicine, Llandough Hospital, \\ Penarth, South Glamorgan, UK
}

SUMMARY The in vivo effect of various cytotoxic drugs and cranial irradiation on neutrophil chemotaxis was tested in 62 children with acute lymphoblastic leukaemia and in 10 patients with other malignant disease. Cranial radiotherapy had a transient adverse effect on neutrophil chemotaxis after completion of the course which was most marked in children. Methotrexate (MTX) and 6-mercaptopurine (6-MP) alone and in combination had a variable effect on chemotaxis, which was most marked nine days after the end of the course. The effect of 6-MP was clearly dose-related, but continuous therapy $\left(75 \mathrm{mg} / \mathrm{m}^{2}\right.$ day $)$ had the greatest inhibitory effect of all the regimens tested.

The in vitro effect was studied in 48 leukaemics and in 85 controls (adults and children); all the patients with leukaemia had been off treatment for at least six months. No difference was found between the effects of drugs tested on control or leukaemic cells. The greatest inhibitory effect was found with vinblastine, adriamycin, 6-MP, and vincristine, all of which were closely dose-dependent. MTX, prednisolone, and asparaginase had no effect on chemotaxis when tested in this way.

Previous studies have shown that cranial radiotherapy and antileukaemic drugs adversely affect neutrophil function in acute lymphoblastic leukaemia in remission. ${ }^{1-3} \mathrm{~A}$ significant correlation between impaired neutrophil chemotaxis and the incidence and severity of bacterial infection confirmed the importance of this function. ${ }^{2}$ Furthermore, an increased morbidity and mortality from infection in the post-irradiation period has been reported ${ }^{4} 5$ with a significant reduction in infection when the dose of concurrent cytotoxic therapy was reduced. ${ }^{4}$

With the known association of increased remission deaths with more intensive antileukaemic treatment, ${ }^{6}$ we decided to study the effect of commonly used cytotoxic drugs and cranial radiation on neutrophil chemotaxis. Also, in view of the increasing preference for combination chemotherapy in a maximum dose, often limited only by severe neutropenia, we considered it was necessary to know whether different combinations of drugs, dosage, or pulsed or continuous administration had any effect on neutrophil chemotaxis.

\section{Material and methods}

IN VIVO EFFECT

Studies were carried out in 14 patients who had received cranial radiotherapy: eight children with Accepted for publication 16 June 1980 leukaemia had each received $2400 \mathrm{rad}$ in 12 fractions over 21 days, and six patients (four adults and two children) with cerebral tumours had received 3000 $3500 \mathrm{rad}$ in 20-25 fractions over four to five weeks. Chemotactic studies were done before, during, and after completion of radiotherapy. Concurrent chemotherapy consisted of a small daily dose of 6-MP $\left(25 \mathrm{mg} / \mathrm{m}^{2}\right)$ in the former and of dexamethasone (4-8 $\mathrm{mg}$ daily) in the latter.

The effect of MTX and 6-MP in different regimens was tested in 29 individuals. The regimens consisted of simultaneous (studies 1 and 2) or sequential (study 3) administration of MTX and 6-MP, and continuous 6-MP with weekly MTX (study 4). In nine children, continuous 6-MP only was studied in two regimens ( 25 or $75 \mathrm{mg} / \mathrm{m}^{2}$ daily). In 11 children, the effect of prednisolone, $40 \mathrm{mg} / \mathrm{m}^{2}$ a day, was studied. Details of the timing of the study in relation to drug(s) and dosage given are shown in the Table.

In 13 individuals in whom all cytotoxic chemotherapy had been discontinued for at least six months, the effect of a five-day course of 6-MP $\left(200 \mathrm{mg} / \mathrm{m}^{2}\right)$ and MTX $\left(10 \mathrm{mg} / \mathrm{m}^{2}\right)$ given separately was studied. Tests were done before treatment and on day 5 of the treatment course.

Finally, the effect of an infusion of high-dose MTX $\left(1000 \mathrm{mg} / \mathrm{m}^{2}\right.$ given over 4 hours) with subsequent folinic acid recall was studied in four patients with brain tumours. 
Comparison between effect of different drug combination $(s)$ and dose $(s)$ on neutrophil chemotaxis (attractants: casein $(C)$, $\operatorname{serum}(S)$, and random migration $(R))$. Distances travelled in microns

\begin{tabular}{|c|c|c|c|c|c|c|c|c|c|c|c|c|c|c|c|c|c|c|c|c|c|c|c|c|c|c|c|}
\hline \multirow[t]{2}{*}{ 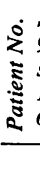 } & \multicolumn{3}{|c|}{$\begin{array}{l}\text { Study } 1 \\
9 \text { days post } \\
\text { simultaneous } \\
M T X(12 \cdot 5)+ \\
6-M P(200)\end{array}$} & \multirow[t]{2}{*}{$\frac{0}{3}$} & \multicolumn{3}{|c|}{$\begin{array}{l}\text { Study } 2 \\
17 \text { days post } \\
\text { simultaneous } \\
M T X(12 \cdot 5)+ \\
6-M P(200)\end{array}$} & \multirow[t]{2}{*}{ 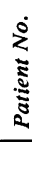 } & \multicolumn{3}{|c|}{$\begin{array}{l}\text { Study } 3 \\
\text { Sequential MTX } \\
(15) \text { and } 6-M P \\
(70)\end{array}$} & \multicolumn{4}{|c|}{ 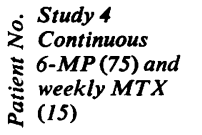 } & \multirow[t]{2}{*}{ 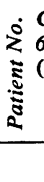 } & \multicolumn{2}{|c|}{$\begin{array}{l}\text { Continuous } \\
6-M P \\
(75)\end{array}$} & \multirow{2}{*}{\multicolumn{2}{|c|}{ 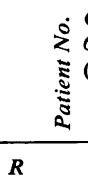 }} & \multicolumn{3}{|c|}{$\begin{array}{l}\text { Continuous } \\
6-M P \\
(25)\end{array}$} & \multirow[t]{2}{*}{$\begin{array}{l}0 \\
\vdots \\
\vdots \\
0 \\
0\end{array}$} & \multicolumn{3}{|c|}{$\begin{array}{l}\text { Prednisolone } \\
\text { (40) }\end{array}$} \\
\hline & $C$ & $S$ & $R$ & & $C$ & $S$ & $\boldsymbol{R}$ & & $C$ & $S$ & $\boldsymbol{R}$ & & $C$ & $S$ & $\boldsymbol{R}$ & & $C$ & $S$ & & & $C$ & $S$ & $\boldsymbol{R}$ & & $C$ & $S$ & $\boldsymbol{R}$ \\
\hline $\begin{array}{l}1 \\
2 \\
3 \\
4\end{array}$ & $\begin{array}{l}81 \\
64 \\
21 \\
93\end{array}$ & $\begin{array}{l}86 \\
63 \\
39 \\
66\end{array}$ & $\begin{array}{l}83 \\
55 \\
47 \\
60\end{array}$ & $\begin{array}{r}5 \\
6 \\
7 \\
8 \\
9 \\
10 \\
11\end{array}$ & $\begin{array}{r}76 \\
55 \\
113 \\
106 \\
95 \\
79 \\
-\end{array}$ & $\begin{array}{r}75 \\
54 \\
54 \\
111 \\
83 \\
54 \\
74\end{array}$ & $\begin{array}{l}52 \\
42 \\
93 \\
53 \\
57 \\
73\end{array}$ & $\begin{array}{l}12 \\
13 \\
14 \\
15 \\
16 \\
17 \\
18 \\
19\end{array}$ & $\begin{array}{r}65 \\
87 \\
61 \\
108 \\
74 \\
115 \\
94 \\
74\end{array}$ & $\begin{array}{l}57 \\
66 \\
75 \\
74 \\
52 \\
75 \\
75\end{array}$ & $\begin{array}{l}53 \\
54 \\
49 \\
60 \\
64 \\
- \\
- \\
57\end{array}$ & $\begin{array}{l}20 \\
21 \\
22 \\
23 \\
24 \\
25 \\
26 \\
27 \\
28 \\
29\end{array}$ & $\begin{array}{r}65 \\
87 \\
93 \\
90 \\
55 \\
55 \\
91 \\
118 \\
99 \\
81\end{array}$ & $\begin{array}{l}57 \\
72 \\
96 \\
63 \\
54 \\
44 \\
91 \\
96 \\
77 \\
73\end{array}$ & $\begin{array}{l}47 \\
51 \\
81 \\
70 \\
42 \\
30 \\
69 \\
63 \\
60 \\
75\end{array}$ & $\begin{array}{l}30 \\
31 \\
32\end{array}$ & $\begin{array}{r}47 \\
45 \\
101\end{array}$ & $\begin{array}{l}50 \\
45 \\
68\end{array}$ & $\begin{array}{l}49 \\
39 \\
72\end{array}$ & $\begin{array}{l}33 \\
34 \\
35 \\
36 \\
37 \\
38\end{array}$ & $\begin{array}{r}80 \\
78 \\
90 \\
77 \\
92 \\
102\end{array}$ & $\begin{array}{l}91 \\
92 \\
91 \\
79 \\
84 \\
56\end{array}$ & $\begin{array}{l}90 \\
84 \\
78 \\
75 \\
80 \\
52\end{array}$ & $\begin{array}{l}39 \\
40 \\
41 \\
42 \\
43 \\
44 \\
45 \\
46 \\
47 \\
48 \\
49\end{array}$ & $\begin{array}{r}87 \\
85 \\
118 \\
96 \\
55 \\
71 \\
49 \\
67 \\
72 \\
60 \\
76\end{array}$ & $\begin{array}{r}79 \\
63 \\
123 \\
98 \\
71 \\
71 \\
52 \\
68 \\
60 \\
36 \\
72\end{array}$ & $\begin{array}{l}- \\
58 \\
96 \\
69 \\
68 \\
68 \\
52 \\
52 \\
43 \\
35 \\
61\end{array}$ \\
\hline & $\begin{array}{c}\text { an m } \\
65\end{array}$ & $\begin{array}{r}\text { igrat } \\
64\end{array}$ & ion ( & $\mu \mathrm{m})$ & 87 & 72 & 62 & & 85 & 68 & 56 & & 83 & 72 & 59 & & 64 & 54 & 53 & & 87 & 82 & 77 & & 76 & 72 & 60 \\
\hline
\end{tabular}

Figures in parentheses represent daily dose $\left(\mathrm{mg} / \mathrm{m}^{2}\right)$. Control values for 6-15 year age group (casein $89(12)$, serum $79(12)$, random migration 67 (16)).

IN VITRO EFFECT OF CYTOTOXIC DRUGS

Neutrophils from 85 normal individuals (adults and children) and from 48 children with leukaemia in remission (off all drugs for at least six months) were incubated for 1 hour with and without the particular drug before the chemotactic response was tested in the usual way. Drugs tested were vincristine, vinblastine, MTX (intrathecal preparation), 6-MP (sodium preparation supplied by Wellcome Foundation Ltd), methyl prednisolone, adriamycin, and asparaginase. Different drug concentrations were used (at, above, and below the accepted therapeutic range).

\section{CHEMOTACTIC ASSAY}

Wilkinson's modification of the Boyden technique? was used, and the chemotactic index was measured by the leading front technique. ${ }^{8}$ This involved measuring the distance travelled (in microns) by the leading front of cells during $\mathbf{5 0}$ minutes' incubation. Attractants used were casein $(5 \mathrm{mg} / \mathrm{ml})$ and $20 \%$ pooled normal human serum (activated by Escherichia coli endotoxin). Random migration was assayed by the same method using $20 \%$ activated serum in both compartments. Reproducibility of the method was within $10 \%$ in the same individual (chamber/chamber, filter/filter, and day/day). However, a wider person/person variation was found in the normal adults, with a mean and SD of 104 (12) for casein, 95 (15) for serum, and 79 (17) for random migration. An age-dependent effect was found in normal children. ${ }^{3}$ Age-matched controls were therefore used for comparison. The normal mean and SD of the 6-15 year age group was 89 (12) for casein, 79 (12) for serum, and 67 (16) for random migration.

\section{Results}

\section{EFFECT OF RADIOTHERAPY}

Serial results are shown in Figure 1. A downward trend in values is seen in both groups, which in the children reached the bottom of a trough at the end of the radiotherapy course. Statistical comparison with the pretreatment values was significant only in the children at this point (Student $t$ test, $\mathrm{P}<0.02$ casein, $P<0.05$ random migration). However, when this comparison was made with the control values, a significant difference in both groups was found at this point (Student $t$ test: children $P<0.001$ casein, serum, random migration; adults $P<0.05$ casein). Recovery was complete at week 13 in the children but not in the adults.

\section{EFFECT OF CYTOTOXIC DRUGS}

All results are given in the Table. With the exception o of 6-MP $\left(25 \mathrm{mg} / \mathrm{m}^{2}\right)$, all the other drugs, alone or in $N$ combination, had a suppressive effect on chemotaxis in some individuals. This was most marked in those on continuous 6-MP at a daily dose of 75 $\mathrm{mg} / \mathrm{m}^{2}$ (Student $t$ test $\mathrm{P}<0.01$ casein and serum), and on the ninth day after a course of MTX and $\mathscr{\mathscr { C }}$ 6-MP (Student $t$ test $P<0.01$ and $<0.05$ casein and serum respectively).

\section{EFFECT OF AN ISOLATED COURSE OF MTX AND 6-MP}

None of these children had received cytotoxic chemo- 


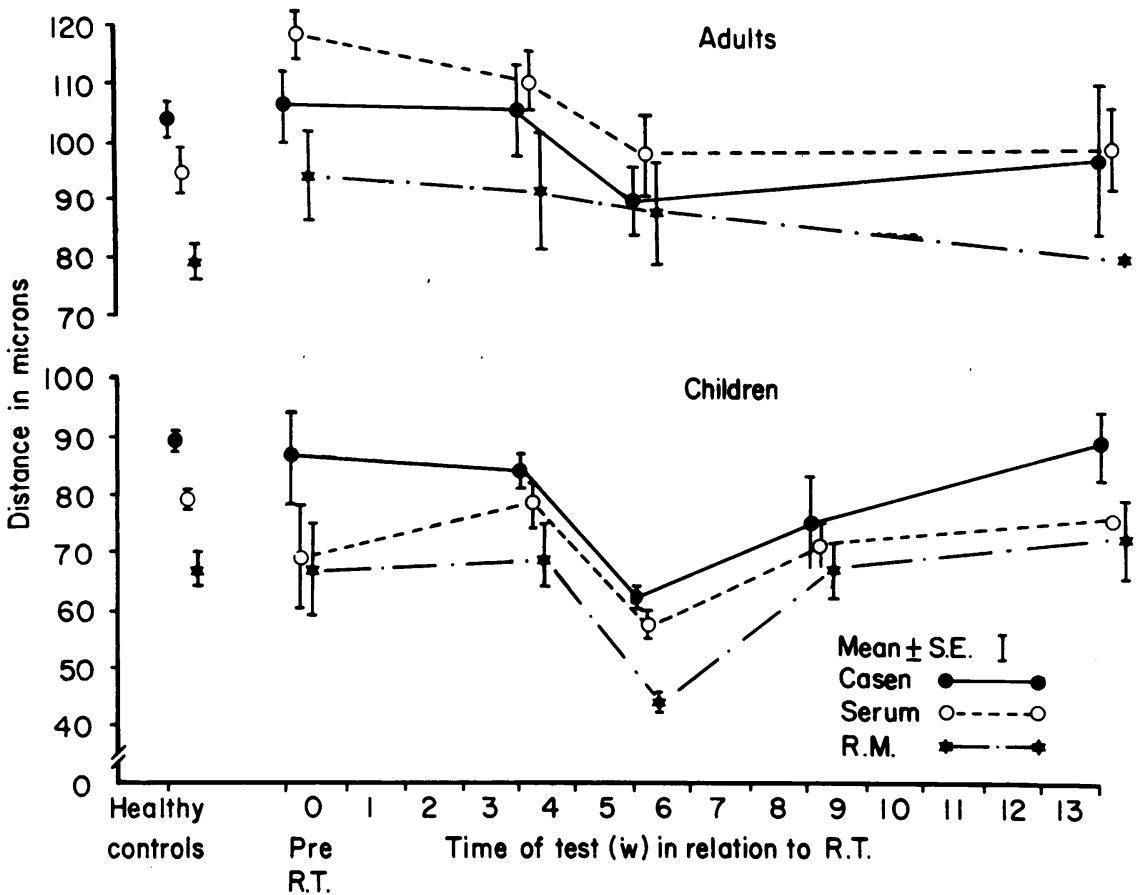

Fig. 1 Neutrophil chemotaxis and random migration before, during, and after cranial irradiation in 10 children ( 8 with leukaemia and 2 with brain tumours) and four adults. Radiotherapy was given from weeks 1 to 8 in the children with leukaemia and from weeks 1 to 3 in the brain tumour patients.

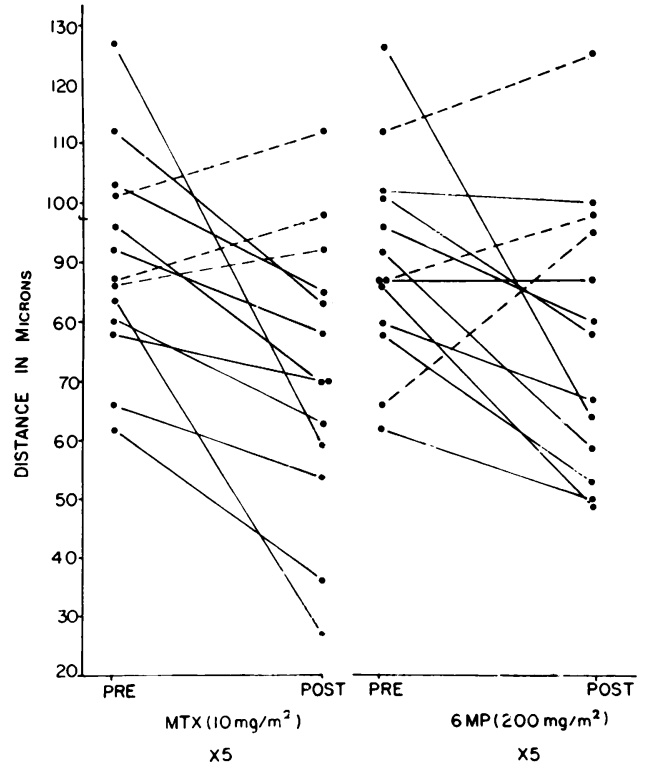

Fig. 2 Chemotaxis before and after a five-day course of $M T X$ and 6-MP given separately. A marked inhibitory effect on chemotaxis was found in both groups but was significant only in the methotrexate group $(\mathrm{P}<0.01)$. All these children were in clinical remission and had had no cytotoxic drugs for at least six months. therapy in the preceding six months and so the effect of these drugs is specific (Fig. 2). A significant reduction in chemotaxis was found in 10 of 13 children receiving MTX (paired $t$ test $P<0.01$ ). However, although eight of the 13 receiving 6-MP had some impairment of chemotaxis on day 5 , the difference was not significant (paired $t$ test $\mathrm{P}<0 \cdot 1$ ).

EFFECT OF HIGH-DOSE MTX (1000 MG/ $\left.\mathrm{M}^{2}\right)$ WITH FOLINIC ACID RECALL

Measurements were made before and 1 hour, 24 hours, and seven days after completion of the methotrexate infusion. Chemotaxis was found to be normal in the four individuals tested at each study point; the overall mean for each period was 96,91 , 102, and 109 microns.

\section{IN VITRO EFFECT OF CYTOTOXIC DRUGS}

The effect of each drug was examined individually. No difference between normal and leukaemic neutrophils was found. The data for each drug at each concentration were pooled. A dose response curve was drawn for each drug, using the reciprocal of the distance travelled in microns $\times 10^{2}$ on the $y$ axis against drug concentration on the $\mathrm{x}$ axis (Fig. 3 ).

The most profound inhibitory effect on chemotaxis was found with vinblastine, adriamycin, 6-MP and vincristine. A dose dependent effect was 


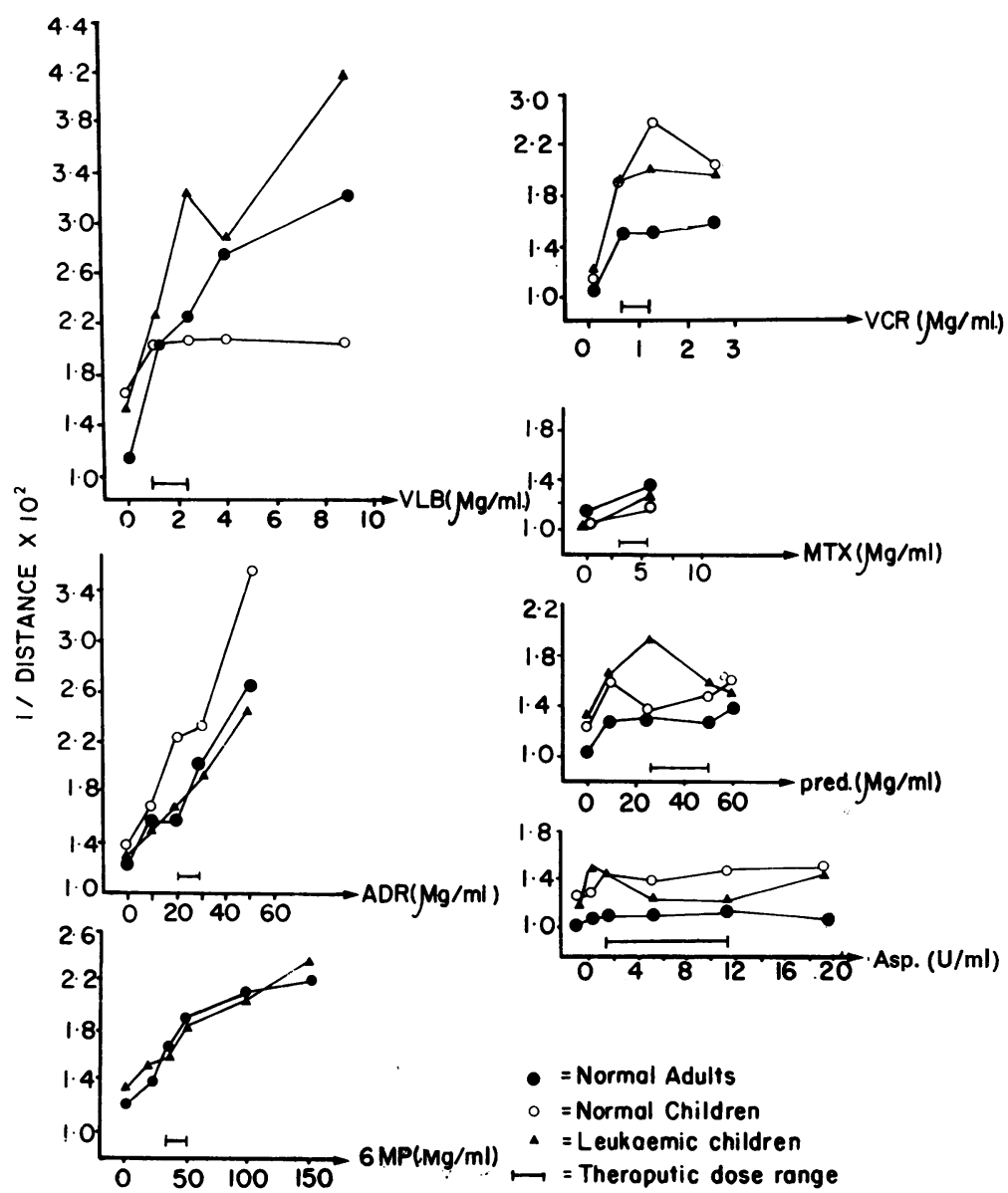

Fig. 3 Chemotactic ability of neutrophils from patients with leukaemia (in remission) and controls (adults and children) after incubation of these cells with cytotoxic drugs. The drugs used were vinblastine (VLB), adriamycin $(A D R)$, 6-mercaptopurine (6-MP), vincristine (VCR), methotrexate (MTX), prednisoione (pred), and asparaginase (Asp). Varying drug concentrations $(\mu \mathrm{g} / \mathrm{ml})$ expressed on the $x$ axis. Chemotaxis expressed as 100 times the reciprocal of the migration distance (microns) on the $y$ axis.

noted with the first three drugs in particular. It was interesting that the inhibitory effect of adriamycin and 6-MP was found at a lower dose than the recommended therapeutic level (paired $t$ test: adriamycin $P<0.05,6-M P P<0.02$ ). Furthermore, the in vitro effect of 6-MP was more marked than the in vivo effect of a high dose $\left(200 \mathrm{mg} / \mathrm{m}^{2}\right)$ given daily for five days. In contrast, MTX, prednisolone, and asparaginase had no effect on chemotaxis when tested in this way.

\section{Discussion}

The immunosuppressive action of some cytotoxic drugs is well recorded, but little is known about their anti-inflammatory effect. Chemotaxis, phagocytosis, and intracellular digestion of ingested organisms are important steps in the defence mechanism against pyogenic infection and in the antiinflammatory reaction. Very few studies on the effect of cytotoxic drugs on neutrophil chemotaxis 
have been reported. In a previous study we drew attention to the impaired cellular aspect of neutrophil chemotaxis in leukaemic individuals in remission on cytotoxic drugs and suggested that the suboptimal chemotactic response found was due to the effect of cytotoxic drugs. ${ }^{2}$ However, it was difficult to know whether the difference found at different stages of follow-up was due to individual variation or was the effect of drugs. Serial studies in any one patient were possible on only a few occasions, and a systematic study of specific drug combinations was not done. In this study, the effect of specific drug combinations in individual patients was observed but not individual responses to different treatment schedules.

Cranial radiotherapy was shown to have a transient adverse effect on neutrophil chemotaxis, more marked in the children than the adults. The restoration of values to the pretreatment level in the former may be due to the short period of radiation ( $3 v 5$ weeks) that they received. Other workers ${ }^{1}$ have shown impaired bactericidal capacity but not phagocytosis after cranio/spinal irradiation. We did not study these aspects of neutrophil function on this occasion, but in an earlier study ${ }^{9}$ we were unable to demonstrate any adverse effect on these mechanisms and thought that the spinal component of irradiation probably affected this aspect of neutrophil function.

We found considerable variation in the effect of MTX given in different ways. When given alone in a small daily dose for five days, a marked inhibitory effect was found (Fig. 2), but a single dose of 1000 $\mathrm{mg} / \mathrm{m}^{2}$ followed by folinic acid recall 4 hours later did not affect chemotaxis. This confirmed the observation by Greenwald ${ }^{10}$ that the duration of exposure to MTX is more important than the height of the blood level achieved. The in vitro effect of this drug was minimal, thus confirming that circulating MTX has no direct effect on neutrophil chemotaxis.

Although the in vivo effect of 6-MP (Fig. 2) on neutrophil chemotaxis was similar to that seen with methotrexate, the in vitro effect of the drug (Fig. 3) was much more marked and very clearly doserelated. Interestingly, although a dose-related effect was seen in the in vivo studies, continuous versus pulsed treatment seemed to have a much greater inhibitory action. Thus the effect of $200 \mathrm{mg} / \mathrm{m}^{2}$ daily for five days was less toxic than a continuous daily dose of $75 \mathrm{mg} / \mathrm{m}^{2}$. However, no inhibitory effect was found if the dose was reduced to $25 \mathrm{mg} / \mathrm{m}^{2}$, even though given continuously, thus suggesting that 6-MP may affect chemotaxis in two ways, namely, an earlier action during cell maturation and an immediate effect of the circulating drug. Although we do not have any data on blood levels, it is unlikely that any free circulating drug would be present 17 days after a course of treatment. Whereas in those patients on continuous therapy an earlier effect on the maturing cell could coexist with the current action of the circulating drug, no enhancement of inhibition occurred when 6-MP and MTX were given together in the in vivo tests. The timing of the test was clearly important, recovery of chemotaxis occurring nine to 17 days after a five-day course of drugs. This time interval was similar to that described by $\mathrm{Craft}^{11}$ in assessing small bowel function after MTX administration.

Corticosteroids affect several aspects of the inflammatory and immune responses. ${ }^{12-15}$ This may explain why prednisolone had an inhibitory effect on chemotaxis in some individuals but not in others. An in vitro effect with prednisolone was not shown. Asparaginase differed from all the other drugs tested in having an extracellular action only on circulating asparagine. It is, therefore, not surprising that the in vitro studies failed to show any effect on chemotaxis.

The most marked in vitro chemotactic inhibitory effect was demonstrated with vinblastine, vincristine, and adriamycin (Fig. 3). The vinca alkaloids are known to have a lytic effect on microtubular structures, and so the effect on neutrophil chemotaxis is not surprising. The dose-related effect shown by vinblastine may be due to additional actions on other intracellular proteins or nucleocytoplasmic structures. The mode of action of adriamycin (an anthracycline antibiotic) and actinomycin $\mathrm{D}$ are similar, and interestingly the latter drug is known to have an inhibitory effect on in vitro neutrophil chemotaxis. ${ }^{16}$

Although the dose dependency of the vinca alkaloids and adriamycin was clearly shown, these drugs are not normally associated with an increased susceptibility to infection. This is possibly due to their marked myelosuppressive action and to the fact that they are given episodically and so affect a single generation of cells.

The in vivo studies have shown that certain cytotoxic drugs given in conventional dosage can have a marked effect on neutrophil chemotaxis in some individuals. The fact that this adverse effect can be enhanced by circulating drugs (in vitro effect) is important and could explain the increased susceptibility to infection in some patients on a continuous regimen rather than a pulsed schedule. These mechanisms should, therefore, be considered in patients so treated who suffer from repeated infections. Modification of the dose, and pulsed rather than continuous treatment, may be associated with a definite improvement in neutrophil function without any loss of the anti-cancer effect. 
Little is known about the in vivo effect of antibiotics on neutrophil chemotaxis, although in vitro studies have shown a marked inhibition of chemotaxis by some drugs, notably, rifampicin, chloramphenicol, sodium fusidate, and tetracycline. ${ }^{17}$ The mode of action of some antibiotics is very similar to that of cytotoxic drugs, and so it is not surprising that a function such as neutrophil chemotaxis might be affected. Surprisingly little, however, is known about the anti-cancer effect of antibiotics and cytotoxic drugs used togethe1, or about a possible additive inhibitory effect on a function such as neutrophil chemotaxis in a patient treated with cytotoxic drugs who subsequently develops an infection and requires an antibiotic. Further studies are needed to examine the effects of these drugs given together, from both a tumouricidal and antiinflammatory aspect.

\section{References}

${ }^{1}$ Baehner RL, Neiburger RG, Johnson DE, Murrmann SM. Transient bactericidal defect of peripheral blood phagocytes from children with acute lymphoblastic leukaemia receiving craniospinal irradiation. $N$ Engl J Med 1973; 289:1209-13.

2 Al-Nakeeb SN, Thompson EN. Neutrophil chemotaxis in acute lymphoblastic leukaemia. Humoral and cellular aspects. Arch Dis Child 1980;55:299-303.

${ }^{3}$ Al-Nakeeb SN, Thompson EN. Assessment of neutrophil chemotaxis and random migration in childhood; comparison between leading front and lower surface count method. Arch Dis Child 1980;55:296-8.

${ }^{4}$ MacLennan IC, Peto J, Kay HEM. Analysis of treatment of childhood leukaemia V. Advantage of reduced chemotherapy during and immediately after cranial irradiation. Br J Cancer 1977;36:625-33.

5 Waller CS, MacLennan ICM, Campbell AC, Festenstein M, Kay HEM. Analysis of treatment in childhood leukaemia III. Independence of lymphopenia induced by irradiation and by chemotherapy. Br J Haematol 1977; $35: 597-612$.
${ }^{6}$ Simone JV, Holland E, Johnson W. Fatalities during remission of childhood leukaemia. Blood 1972;39:75970.

7 Wilkinson PC. Chemotaxis and inflammation. Edinburgh: Churchill Livingstone, 1974.

${ }^{8}$ Zigmond SH, Hirsch JG. Leukocyte locomotion and chemotaxis. New methods for evaluation and demonstration of cell derived chemotactic factor. $J$ Exp Med 1973;137:387-410.

9 Thompson EN, Williams R. Bactericidal capacity of peripheral blood leucocytes in relation to bacterial infections in acute lymphoblastic leukaemia in childhood. J Clin Pathol 1974;27:906-10.

${ }^{10}$ Greenwald ES. Cancer chemotherapy. Medical Outline Series. Medical Examination Publishing Co Inc, 1973; 43.

${ }^{11}$ Craft AW, Kay HEM, Lawson DN, McElwain TJ. Methotrexate induced malabsorption in children with acute lymphoblastic leukaemia. Br Med J 1977;ii:1511-2.

${ }^{12}$ Boggs DR, Athens JW, Cartwright GE, Wintrobe MM. The effect of adrenal glucocorticosteroids upon the cellular composition of inflammatory exudates. $\mathrm{Am} \mathrm{J}$ Pathol 1964;44:763-73.

${ }^{13}$ Rinehart JJ, Sagone AL, Balcerzak SP, Ackerman GA, Lobuglio AF. Effects of corticosteroid therapy on human monocyte function. $N$ Engl J Med 1975;292: 236-41.

14 Ward PA. The chemosuppression of chemotaxis. $J$ Exp Med 1966;124:209-26.

${ }^{15}$ Cline MJ, Melmon KL. Plasma kinins and cortisol: a possible explanation of the anti-inflammatory action of cortisol. Science 1966;153:1135-8.

${ }^{16}$ Carruthers BM. Leucocyte motility. II Effect of absence of glucose in medium; effect of presence of deoxyglucose, dinitrophenol, puromycin, acintomycin D and trypsin on the response to chemotactic substance; effect of segregation of cells from chemotactic substance. Can $J$ Physiol Pharmacol 1967;45:269-80.

${ }^{17}$ Forsgren A, Schmeling D. Effect of antibiotics on chemotaxis in human leucocytes. Antimicrob Agents Chemother $1977 ; 11: 580-4$.

Requests for reprints to: Dr EN Thompson, Department of Child Health, Welsh National School of Medicine, Llandough Hospital, Penarth, South Glamorgan CV6 1WX. 